University of New Hampshire

University of New Hampshire Scholars' Repository

Space Science Center

Institute for the Study of Earth, Oceans, and

Space (EOS)

2000

\title{
Summary of the first COMPTEL source catalogue
}

\author{
V Schonfelder \\ Max-Planck-Institut für extraterrestrische Physik \\ K Bennett \\ ESTEC \\ J J. Blom \\ Space Research Organization of the Netherlands \\ H Bloemen \\ Space Research Organization of the Netherlands \\ W Collmar \\ Max-Planck-Institut für extraterrestriche Physik
}

See next page for additional authors

Follow this and additional works at: https://scholars.unh.edu/ssc

Part of the Astrophysics and Astronomy Commons

\section{Recommended Citation}

Summary of the first COMPTEL source catalogue Schönfelder, V. and Bennett, K. and Blom, J. J. and Bloemen, H. and Collmar, W. and Connors, A. and Diehl, R. and Hermsen, W. and lyudin, A. and Kippen, R. M. and Knödlseder, J. and Kuiper, L. and Lichti, G. G. and McConnell, M. and Morris, D. and Much, R. and Oberlack, U. and Ryan, J. and Stacy, G. and Steinle, H. and Strong, A. and Suleiman, R. and van Dijk, R. and Varendorff, M. and Winkler, C. and Williams, O. R., AIP Conference Proceedings, 510, 596-600 (2000), DOl:http://dx.doi.org/10.1063/1.1303272

This Conference Proceeding is brought to you for free and open access by the Institute for the Study of Earth, Oceans, and Space (EOS) at University of New Hampshire Scholars' Repository. It has been accepted for inclusion in Space Science Center by an authorized administrator of University of New Hampshire Scholars' Repository. For more information, please contact Scholarly.Communication@unh.edu. 


\section{Authors}

V Schonfelder, K Bennett, J J. Blom, H Bloemen, W Collmar, A Connors, R Diehl, W Hermsen, A lyudin, R M. Kippen, J Knodlseder, L Kuiper, G G. Lichti, Mark L. McConnell, D Morris, R Much, U Oberlack, James M.

Ryan, G Stacy, H Steinle, A W. Strong, R Suleiman, R VanDijk, M Varendorff, C Winkler, and O R. Williams 


\section{AIP | Proceedings}

\section{Summary of the first COMPTEL source catalogue}

V. Schönfelder, K. Bennett, J. J. Blom, H. Bloemen, W. Collmar, A. Connors, R. Diehl, W. Hermsen, A. lyudin, R. M. Kippen, J. Knödlseder, L. Kuiper, G. G. Lichti, M. McConnell, D. Morris, R. Much, U. Oberlack, J. Ryan, G. Stacy, H. Steinle, A. Strong, R. Suleiman, R. van Dijk, M. Varendorff, C. Winkler, and O. R. Williams

Citation: AIP Conference Proceedings 510, 596 (2000); doi: 10.1063/1.1303272

View online: http://dx.doi.org/10.1063/1.1303272

View Table of Contents: http://scitation.aip.org/content/aip/proceeding/aipcp/510?ver=pdfcov

Published by the AIP Publishing

\section{Articles you may be interested in}

Gamma ray astronomy

AIP Conf. Proc. 516, 195 (2000); 10.1063/1.1291477

Data analysis techniques for stereo IACT systems

AIP Conf. Proc. 515, 318 (2000); 10.1063/1.1291386

AGILE: A gamma-ray mission

AIP Conf. Proc. 510, 746 (2000); 10.1063/1.1303299

The Very Energetic Radiation Imaging Telescope Array System (VERITAS)

AIP Conf. Proc. 510, 637 (2000); 10.1063/1.1303279

The Solar Tower Atmospheric Cherenkov Effect Experiment (STACEE): New results at $100 \mathrm{GeV}$ AIP Conf. Proc. 510, 632 (2000); 10.1063/1.1303278 


\title{
Summary of the First COMPTEL Source Catalogue
}

\author{
V. Schönfelder*, K. Bennett"l, J.J. Blom ${ }^{\dagger}$, H. Bloemen ${ }^{\dagger}$, \\ W. Collmar*, A. Connors ${ }^{\ddagger}$, R. Diehl*, W. Hermsen ${ }^{\dagger}$, A. Iyudin*, \\ R.M. Kippen ${ }^{\ddagger}$, J. Knödlseder ${ }^{\S}$, L. Kuiper ${ }^{\dagger}$, G.G. Lichti*, \\ M. McConnell ${ }^{\ddagger}$, D. Morris ${ }^{\ddagger}$, R. Much ${ }^{\|}$, U. Oberlack* ${ }^{*}$ J. Ryan ${ }^{\ddagger}$, \\ G. Stacy ${ }^{\ddagger}$, H. Steinle*, A. Strong*, R. Suleiman ${ }^{\ddagger}$, R. van Dijk", \\ M. Varendorff*, C. Winkler"l, and O.R. Williams $\|$ \\ * Max-Planck-Institut für extraterrestrische Physik, D-85\%,0 Garching, Germany \\ ${ }^{\dagger} S R O N$-Utrecht, Sorbonnelaan $2, N L-3584$ CA Utrecht, The Netherlands \\ $\ddagger$ Space Sience Center, University of New Hampshire, Durham, NH 03824-3525, USA \\ $\|$ Astrophysics Division, ESTEC, NL-2200 AG Noordwijk, The Netherlands \\ ${ }^{\S}$ Centre d'Etude Spatiale des Rayonnements (CESR), BP 4336, F-31029 Toulouse Cedex, France
}

\section{INTRODUCTION}

The imaging Compton telescope COMPTEL aboard NASA's Compton GammaRay Observatory has opened the $\mathrm{MeV}$ gamma-ray band as a new window to astronomy. COMPTEL provided the first complete all-sky survey in the energy range 0.75 to $30 \mathrm{MeV}$. The catalogue, presented here, is largely restricted to published results from the first five years of the mission (up to Phase IV / Cycle-5). In a few cases, more recent results have been added.

The catalogue contains firm as well as marginal detections of continuum and line emitting sources and presents upper limits for various types of objects. The numbers of the most significant detections are 32 for steady sources and 31 for gamma-ray bursters. Among the continuum sources, detected so far, are spindown pulsars, stellar black-hole candidates, supernova remnants, interstellar clouds, nuclei of active galaxies, gamma-ray bursters, and the Sun during solar flares. Line detections have been made in the light of the $1.809 \mathrm{MeV}{ }^{26} \mathrm{Al}$ line, the 1.157 $\mathrm{MeV}{ }^{44} \mathrm{Ti}$ line, the 847 and $1238 \mathrm{keV}{ }^{56} \mathrm{Co}$ lines, and the neutron capture line at $2.223 \mathrm{MeV}$. For the identification of galactic sources, a modelling of the diffuse galactic emission is essential. Such a modelling at this time does not yet exist at the reqired degree of accuracy. Therefore, a second COMPTEL source catalogue will be produced after a detailed and accurate modelling of the diffuse interstellar emission has become possible.

Here, only a summary of the First COMPTEL Source Catalogue is given. The

CP510, The Fifth Compton Symposium, edited by M. L. McConnell and J. M. Ryan (c) 2000 American Institute of Physics 1-56396-932-7/00/\$17.00 
complete catalogue will appear in the Astronomy and Astrophysics Supplement Series [1].
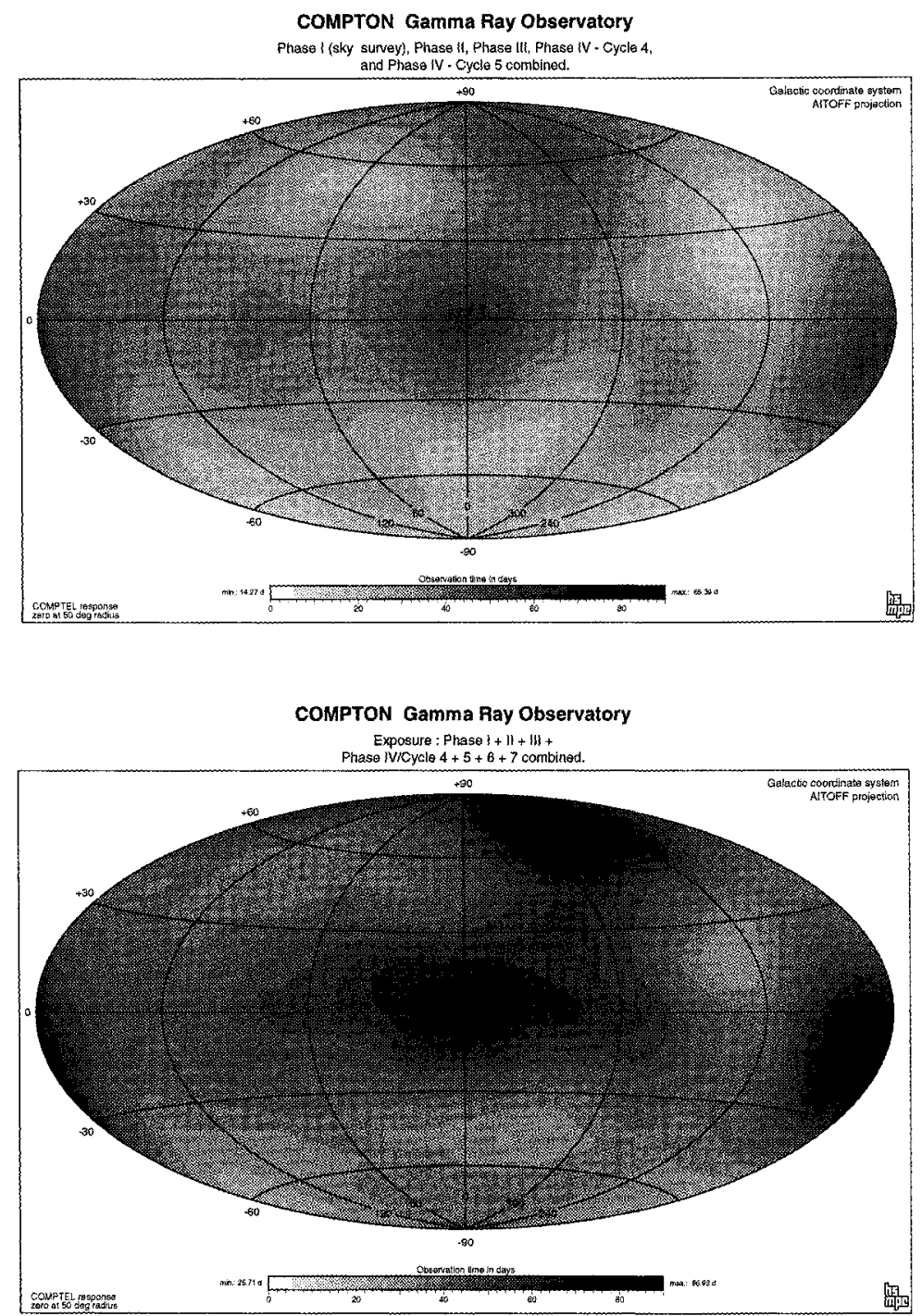

FIGURE 1. COMPTEL Exposure Maps. Top: Phase I to Phase IV / Cycle-5 (April 1991 to October 1996). Bottom: Phase I to Phase IV /Cycle-7 (April 1991 to December 1998). 


\section{OBSERVATIONS AND EXPOSURES}

The effective COMPTEL exposure of the entire sky from the sum of all observations from the beginning of the mission to Phase IV / Cycle-5 is presented in Fig. 1 (top). For illustration, the improvement in exposure up to Phase IV / Cycle-7 is shown in Fig. 1 (bottom), as well. The deepest exposures were obtained in the Galactic Center and anticenter region, where effective observation times up to 6 . $10^{6}$ (about 70 days) have been obtained.

\section{COMPTEL SENSITIVITY}

In its telescope mode COMPTEL has an unprecedented sensitivity. Within a 2-week observation period it can detect sources, which are about 10-times weaker than the Crab. By adding up all data from a certain source that were obtained over the entire duration of the mission, higher sensitivities can be obtained. Table 1 summarizes the achieved point-source sensitivities for a 2-week exposure in Phase I of the mission $\left(t_{e f f} \sim 3.5 \cdot 10^{5} \mathrm{sec}\right)$, and for the ideal cases, when all data from a certain source in the Galactic Center or anticenter (where the exposure is highest) are added from either Phase I to III $\left(\mathrm{t}_{e f f} \sim 2.5 \cdot 10^{6} \mathrm{sec}\right)$ or Phase I to IV /Cycle-5 $\left(\mathrm{t}_{\text {eff }} \sim 6 \cdot 10^{6} \mathrm{sec}\right)$. (Phase I ended in November 1992, Phase III in October 1993, and Phase IV/Cycle-5 in October 1996.)

From this table rough upper limits can be derived for those objects, which are not contained in the catalogue by deriving the effective exposure from Figure 1.

TABLE 1. From this table rough upper limits can be derived for those objects, which are not contained in the source catalogue, by deriving the effective exposure from Fig. 1.

\begin{tabular}{c|c|c|c}
\hline & \multicolumn{3}{|c}{$3 \sigma$ Flux Limits $\left[10^{-5}\right.$ photons $\left.\mathrm{cm}^{-2} \mathrm{sec}^{-1}\right]$} \\
$\mathrm{E}_{\gamma}[\mathrm{MeV}]$ & 2 weeks in Phase 1 & Phase $1+2+3$ & Phase $1+2+3+4$ (Cycle-5) \\
\hline $0.75-1$ & 20.1 & 7.4 & 3.7 \\
$1-3$ & 16.8 & 5.5 & 3.8 \\
$3-10$ & 7.3 & 2.8 & 1.7 \\
$10-30$ & 2.8 & 1.0 & 0.8 \\
1.157 & 6.2 & 2.0 & 1.6 \\
1.809 & 6.6 & 2.2 & 1.6 \\
\hline
\end{tabular}




\section{RESULTS}

Table 2 summarizes the most significant source detections $(\geq 3 \sigma)$ from the main source catalogue paper [1], and Fig. 2 gives an all-sky view of these sources. Six of the listed sources extend over larger areas. Their extent may actually be due to a larger number of - so far - unresolved point sources (see especially Cygnus region in $1.809 \mathrm{MeV}$ [2], GRO J 1823-12 [3], and HVC complex C [3]).

TABLE 2. Summary of Most Significant COMPTEL Source Detections.

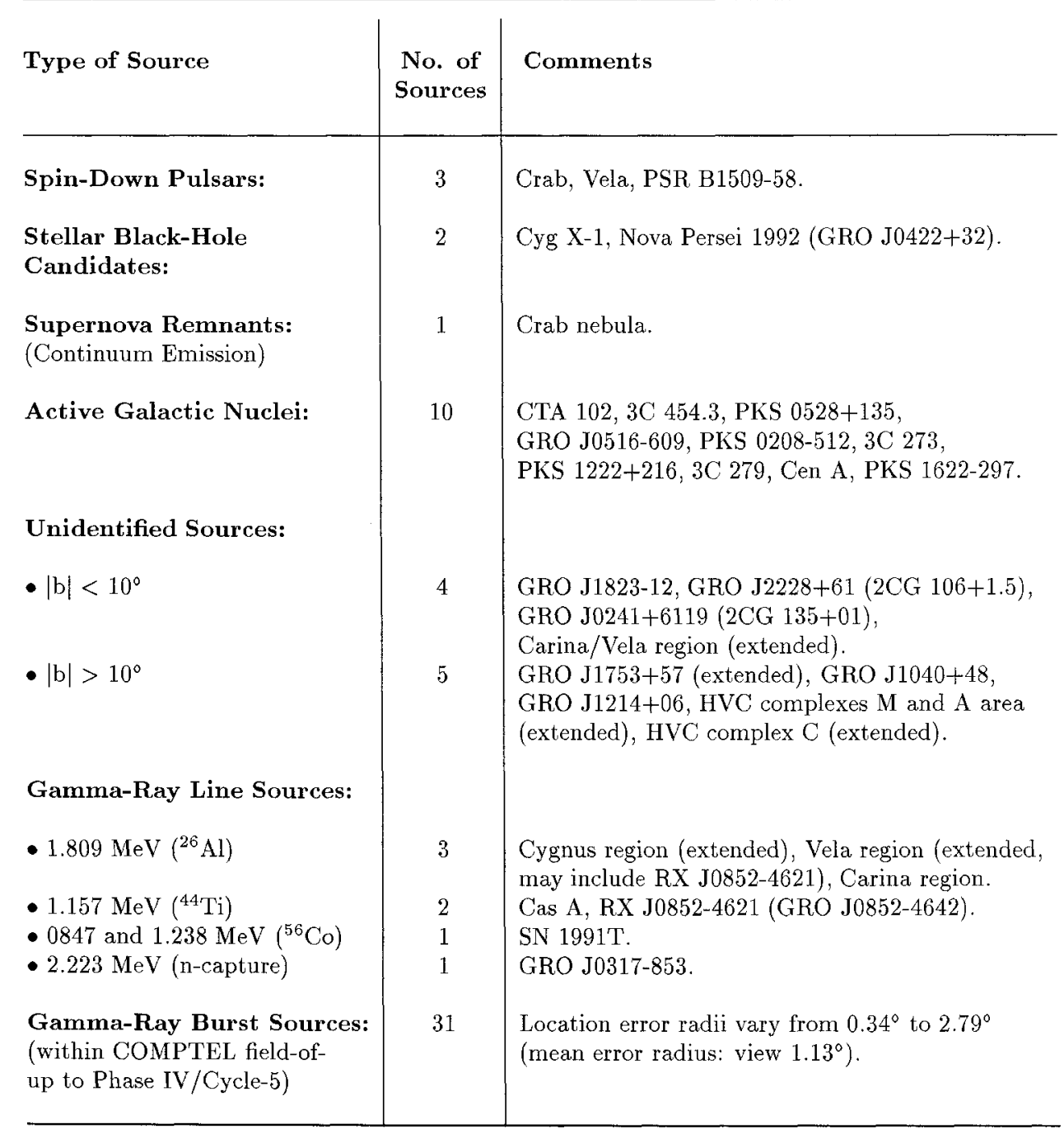


COMPTEL Source Catalogue

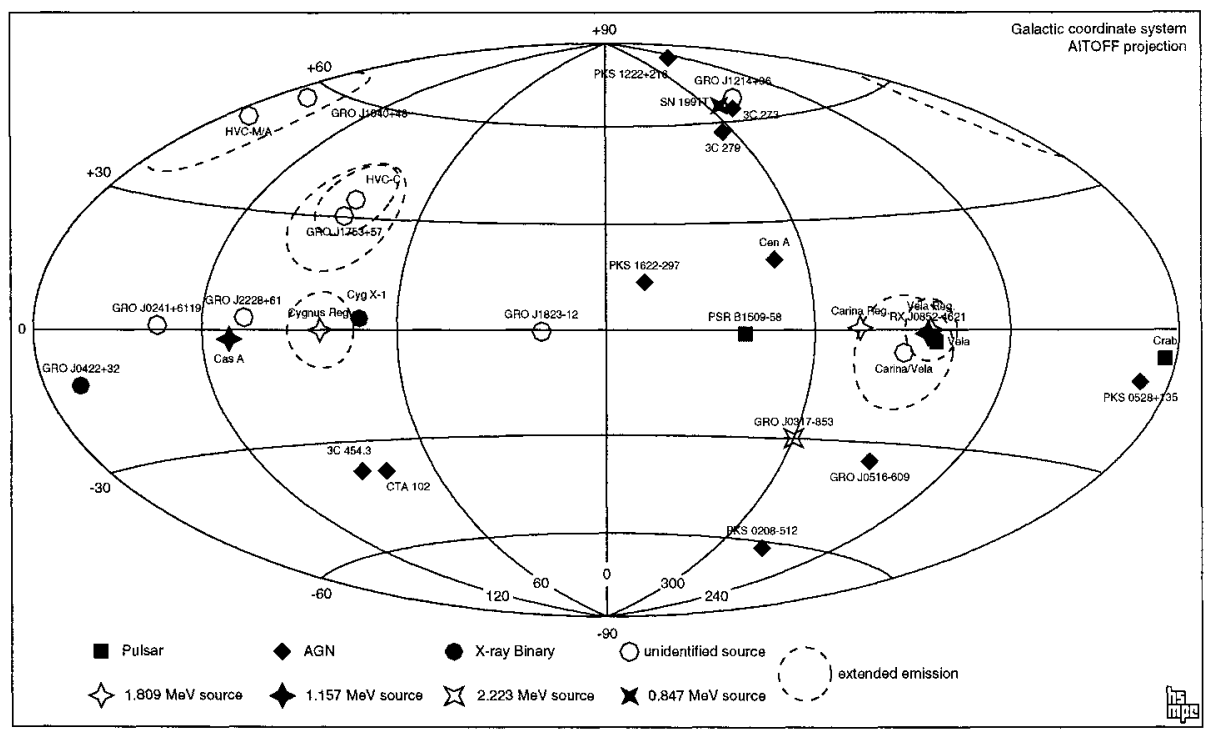

FIGURE 2. All-Sky View of the COMPTEL Source Catalogue.

\section{ACKNOWLEDGEMENT}

The COMPTEL project is supported by the German government through DLR grant 50 Q 9096 8, by NASA under contract NAS5-26645, and by the Netherlands Organization for Scientific Research NWO.

\section{REFERENCES}

1. Schönfelder, V. et al. Astron. $B$ Astrophys. Suppl. Series, submitted for publication. 2. Plüschke, S. et al., these proceedings.

3. Williams, O.R. et al., these proceedings. 